\title{
SANTILLANA Y EL PRERRENACIMIENTO
}

En una de las obras más profundas y completas escritas en nuestra época sobre la literatura del siglo xv, trata María Rosa Lida de Malkiel de caracterizar y situar la posición literaria de Juan de Mena con relación a la Edad Media agónica y a un Renacimiento todavía carente de forma y de seguridad en sus actitudes: "Una concepción histórica superficial y ya superada ha reducido la esencia del Renacimiento al retorno a los clásicos y, aunque hoy nadie la sostenga, la escasa intimidad con los clásicos en el mundo hispánico actual permite comprender que críticos contemporáneos inscriban todavía a Mena en el Renacimiento por la abundancia de sus alusiones a la mitología e historia clásica..." No basta, pues, hacer una estadística de las alusiones al mundo grecorromano. Es preciso, ante todo, ver cómo funciona internamente cada uno de estos elementos en el propósito del poeta, cómo quiere el escritor utilizar su material. "Lo peculiar de Mena, prerrenacentista, es que junto a la alusión y enumeración ejemplares, típicas del didactismo medieval, introduce sistemáticamente la alusión mitológica con sentido ornamental que antes se halla sólo esporádicamente" ${ }^{1}$. Estas breves palabras contienen la esencia de la obra de María Rosa Lida de Malkiel, y nos proporcionan a la vez un valioso esquema para tratar de situar al Marqués de Santillana, que en tantas cosas coincide con Mena, frente a los problemas "técnicos" y vitales de la literatura de su época.

Didactismo, esteticismo: éstos son los dos polos alrededor de los cuales se despliega la compleja y difícil obra de Mena. Un esquema no permite sino un breve deslinde, una posibilidad de exploración. Resulta indispensable, sin embargo, empezar muchas veces por trazar el esquema antes de aventurarse más a fondo en una obra o en un pensamiento. Ahora bien, cuando pensamos en un esquema para Santillana, no nos es posible una polarización en dos sentidos, el didáctico y el "ornamental". Nos es preciso añadir una tercera corriente. Juan de Mena desdeña la inspiración espontánea y descuidada -mejor dicho, poco culta- de lo que se ha llamado poesía popular; Santillana, en cambio, a pesar de adherirse a la actitud aristocrática de Mena, no desdeña cultivar tal poesía, que es precisamente la que más ha interesado en la época moderna.

1 María Rosa Lida de Malkiel, Juan de Mena, poeta del Prerrenacimiento español, El Colegio de México, 1950, pp. 529-530. 
¿Qué papel desempeña lo popular en Santillana, si comparamos, por ejemplo, sus serranillas con las canciones de temas análogos de un escritor puramente medieval, como el Arcipreste de Hita? En un reciente y bien documentado estudio, María Rosa Lida de Malkiel insiste por una parte en la unidad de la obra del Arcipreste ("lo que da unidad estructural al Libro es la personalidad de su autor, que se expresa en forma autobiográfica"), y, por otra, en la importancia de los elementos didácticos, que no funcionan a la manera grecolatina tradicional, sino en forma más libre, y, sobre todo, enlazada con la tradición didáctica hispano-hebrea. Las serranillas del Arcipreste quedarían así supeditadas, en parte por lo menos, al deseo de presentar episodios autobiográficos (o pseudo-autobiográficos) en que fracasa el "loco amor" y en que la descripción de una situación erótica (o con posibilidades eróticas), desventajosa para el Arcipreste, no está superada por ninguna idealización. En sus cánticas de serrana abundan las expresiones y las situaciones groseras, "realistas": "no hay embellecimiento bucólico, y... en este sentido el contraste entre las cánticas de serrana del Arcipreste y las serranillas de Santillana, lugar común de la historia del género en España, está perfectamente justificado" 2. Lo que nos interesa subrayar en este punto es que el didactismo del Arcipreste (que es sin duda sui generis, y que resulta ininteligible fuera de la especial contextura cristianoárabe-hebrea de la Edad Media española) no iba encaminado a una fusión lírica del hombre y la naturaleza. La visión del hombre y la mujer amada dentro de un marco de paisaje propicio al amor, en armonía con los amantes, es un rasgo que desarrollará la poesía renacentista; y de este rasgo, precisamente, nos parece encontrar atisbos en algunos poemas líricos de Santillana, como adelante veremos, lo cual lo convertiría (en forma mucho más explícita que la presencia en su obra de elementos cultos "decorativos" con carácter ornamental) en poeta del Prerrenacimiento.

Ahora bien: aunque en la Edad Media el didactismo pudiera hallarse en todas partes, incluso en los lugares más insospechados -y el artículo de la señora de Malkiel parece bastante convincente cuando sugiere su presencia en las mismas cánticas de serrana-, el sector que menos influencias didácticas sufre, relativamente, es el popular. La corriente popular estilizada, unida a una influencia provenzal y francesa ${ }^{3}$, le ofrece a Santillana una posibilidad de esca-

2 María Rosa Lida DE MAlkiel, "Nuevas notas para la interpretación del Libro de buen amor", NRFH, 13 (1959), en especial pp. 45-46.

3 Véase Pierre Le Gentil, La poésie lyrique espagnole et portugaise à la fin du moyen âge, t. 1, Rennes, 1949, pp. 521-591. Cf. también F. Blasi, "La serranilla spagnuola", ARom, 25 (1941), 86-139. Los enemigos del Marqués lo veían como un "afrancesado": "con habla casi estrangera, / armado como francés" (Coplas de la panadera). Le Gentil repite este juicio ("I'homme qui portait dans les combats une armure française était aussi français par sa façon de penser et 
par, aunque sólo sea en parte, a la actitud didáctica. Por lo demás, Santillana vivía en un país en que, debido al entrelazamiento de culturas y al menor arraigo del feudalismo, era posible "cruzar fronteras" y saltar barreras sociales con mayor facilidad que en Franciat. Se hallaba, pues, en una situación que le permitía dar a sus poemas populares un tono ligeramente distinto del que predominaba en la tradición provenzal, mucho más "moderno" que el de las cánticas del Arcipreste, y sin el didactismo enfático de Mena: condiciones todas que tendían a hacerlo especialmente sensible a los primeros balbuceos de la actitud renacentista.

Un cotejo, incluso rápido, entre la obra de Santillana y la de Mena nos deja la impresión de que los influjos prerrenacentistas incitan a los dos poetas en direcciones distintas, a pesar de los numerosos paralelos que pueden trazarse entre sus estilos. Lo que en Mena es aliento sostenido, dedicación a una empresa difícil, en la que ocupan papel importantísimo los elementos didácticos, es en Santillana jugueteo y diletantismo; el Marqués va probando suerte con géneros y metros diversos, polarizando influjos cultos y populares, franceses, italianos y clásicos. (Desde luego, la ausencia del elemento popular en la obra de Mena es una de las grandes diferencias que lo separan de Santillana).

El talento de Mena se concentra en una obra orgánica, estructurada; el de Santillana se desparrama en tentativas inconexas. Paradójicamente, nos parece que cuando más renacentista se muestra Santillana no es al tratar de aclimatar en España el soneto o al hacer traducir la Iliada, sino al acercarse a los temas populares con una mentalidad nueva, que los transforma en obra de arte con la que el autor convive, en miniatura que, sorprendentemente, se ensancha de pronto para dar cabida entre sus figuras a la del propio poeta.

En contraste con el tratamiento cómico-lírico de la serrana de la Tablada por el Arcipreste, en que lo lírico se levanta con gran dificultad sobre el nivel de lo "vivido", y está todavía al servicio de la experiencia inmediata y prosaica y posiblemente del didactismo moralizador, como sirviéndole de contrapeso; en contraste también

de sentir"), lo cual nos parece inexacto y simplista. Rafael LApesa, La obra literaria del Marqués de Santillana, Madrid, 1957 (estudio magistral, que hemos utilizado a menudo en el presente artículo), precisa con mucha sensatez (pp. 39-41) el verdadero alcance de la influencia francesa y provenzal sobre Santillana. Las serranillas, que combinan la tradición popular española con las influencias francesas, y todo ello en la pluma de un poeta consciente de influencias italianas vagamente renacentistas, resultan así uno de los géneros más complejos y difíciles de analizar, pese a su aparente sencillez formal.

4 Para la situación específica española del siglo xv, véase J. Rubió Balaguer, Vida española en la época gótica, Barcelona, 1943 (especialmente el cap. 2), y los capítulos correspondientes de AmÉrico CAstro, La realidad histórica de España. La situación de las clases sociales era más flúida y estaba menos claramente delimitada que en Francia. 
con la obra descriptiva y de gran aliento de Mena, hay un grupo de poemas de Santillana con los cuales los lectores de hoy siguen deleitándose y que tratan los temas populares con tal refinamiento y agilidad, que implican un dominio del material $y$, a veces, una actitud frente a la vida y al arte que en España sólo se dan en los albores del Renacimiento. Nos referimos a la Serranilla $V$, al Cantar que fizo... a sus fijas loando la su fermosura, y al Villancico... a unas tres fijas suyas.

Lo típico de la pastourelle francesa y provenzal es que el encuentro entre el caballero y la campesina acusa un desnivel, una diferencia social y de puntos de vista que el caballero, incitado por la belleza femenina, trata (muchas veces en vano) de superar, esforzándose por convencer a la muchacha de las ventajas de la vida de ciudad o de castillo, o, con mayor frecuencia, ofreciendo renunciar a sus prerrogativas nobles y adoptar la vida campestre:

$$
\begin{aligned}
& \text { Pastoure, ne t'esmaier! } \\
& \text { mi jeu sont bel: } \\
& \text { avec vos me retenés } \\
& \text { pour garder vos agnels. }
\end{aligned}
$$

Santillana utiliza este recurso en la Mozuela de Bores:
Señora, pastor
seré si queredes:
mandarme podedes
como a servidor.

El poeta, influido probablemente por la tradición francesa y provenzal, siente que hay una barrera social que separa a caballero y serrana, y que es preciso hacer descender al caballero al nivel de la muchacha, o atribuir a ésta un carácter noble, hacerla, por decirlo así, dama honoris causa: "Juro por Santana / que no soys villana".

Didactismo y esteticismo se hallan presentes tanto en Santillana como en Mena. La serranilla como género literario es fruto de una tradición medieval, bien consciente de la división de clases ("aradores, oradores, defensores") $)^{5}$. Santillana, creemos nosotros, no escapa sino en muy raros casos a esta tradición, llevada por la época del gótico florido a la máxima estilización, al más delicado refinamiento. Huizinga y Ortega -sobre todo este último, en En torno a Galileohan subrayado la importancia de la rigidez de las clases sociales en el siglo xv como tema especial para la comprensión del "otoño de la

${ }^{5}$ En la pastourelle, cuyo parentesco con la serranilla es indudable, "el primitivo núcleo de Begegnung y el franco debate en torno al goce sexual queda fuertemente recubierto por el didactismo cortesano, que enseña que una pareja compuesta de un caballero y una muchacha rústica es una pareja desequilibrada" (L. Spitzer, "The Mozarabic lyric and Theodor Frings' theories", CL, 4, 1952, p. 21). 
Edad Media". Santillana es muy consciente de esta rigidez, aunque trate de superarla en cierto momento con su galantería: "que no soys villana".

No es posible; pues, hallar en este caso concreto pruebas de una superación del espíritu medieval. El Renacimiento - sea cual fuere el criterio alrededor del cual tratemos de definir tan ambigua época: en este caso, hablar de "individualismo", de "perspectivismo artístico" o de "platonismo" importa poco, pues los resultados superadores frente a la división de clases sociales acaban por ser parecidostiende, al contrario, a suavizar las divisiones en clases o castas, a plantear problemas que abarcan a toda la "condición humana", según la frase de Montaigne.

Al crítico contemporáneo le resulta a veces difícil percatarse de las dificultades que presentaba para un escritor o un artista no italiano del siglo xv el abandonar la visión del mundo que la tradición gótica y escolástica le había impuesto. $Y$ ello incluso si se trataba de una postura incómoda, incapaz de coordinar la sensibilidad minuciosa al detalle concreto, propia del siglo $\mathrm{xv}$, con las estructuras teóricas y teológicas; incluso, también, cuando el escritor o el artista era un hombre tan inteligente y sensible, tan alerta y abierto a diversas influencias como el Marqués de Santillana. El ciclo renacentista, como observa Wylie Sypher,

no se inicia en realidad sino en el momento en que el estilo llamado gótico se ha agotado -o ha "degenerado", o se ha transformado-, desembocando en un naturalismo que generalmente denota la disolución de una técnica formal. Se puede afirmar que la reintegración del estilo se inició, en Italia por lo menos, a principios del siglo xıv, y se expresa principalmente en las tentativas de las artes de los siglos xv y xvi -pintura, arquitectura, escultura y literatura- por conseguir un nuevo principio formal de composición que dé "unidad" al mundo del artista. Este principio de unidad se encontró en la noción renacentista de proporción armoniosa, relaciones ideales, y la "realización" coherente de una escena o una acción a partir de un punto de vista fijo. El artista, el crítico y el hombre de ciencia del Renacimiento creian que podían dar coherencia a su mundo obedeciendo el Número Aureo y la Probabilidad, que eran las bases del "estilo noble", afirmación del Logos y de la Proporción en cada una de las artes, así como en la física, la astronomía y la filosofía ${ }^{6}$.

Ahora bien: la idea de "proporción armoniosa" no era, por cierto, ajena al Marqués de Santillana, que insiste en el Prohemio acerca de la superioridad del lenguaje medido: "me esfuerço a dezir el metro

6 W. SYPHER, Four stages of Renaissance style: transformations in art and literature, New York, 1956, p. 33 . 
ser antes en tiempo e de mayor perfección e más auctoridad que la soluta prosa" 7 . Y hablando de las Musas:

Tanto me plaçe las Çirras donçellas, en quien non consiste un punto d'amargo: non quieren lo corto, repruevan lo largo e de los oçiosos dan grandes querellas.

Proporción, mesura, justo medio: ideas todas ellas que los escritores renacentistas no tardarían en desarrollar. No es que Santillana afirme que el mundo es un libro escrito en lenguaje matemático, ni que reconozca, como lo hará Castiglione, la existencia de un orden y medida en todas partes, en forma inalterable. Pero su insistencia en las cualidades intrínsecas de la métrica nos permite vislumbrar una sensibilidad que no debía estar muy lejos de la obsesión platónica y matemática de los renacentistas del xvi. Había, por lo menos, gérmenes de tal actitud en un hombre tan consciente de las virtudes de la proporción, la mesura y la armonía.

La idea misma del Renacimiento, es bien sabido, se halla actualmente -y esto ocurre desde hace ya algunos años- en pleno proceso de reelaboración. Insatisfechos con las ideas de Burckhardt, los historiadores del siglo $\mathrm{xx}$ han tratado de sustituir sus esquemas con otros, más variados, a veces en pugna entre sí, y que no han alcanzado una difusión y aceptación universales. Juan Marichal, después de recordar los ataques de Huizinga y otros investigadores actuales contra "el concepto de Renacimiento elaborado por Michelet y por Burckhardt", ataques centrados sobre todo en torno a la idea del "descubrimiento del individuo" ("rasgo esencialmente característico del hombre renacentista según los dos grandes historiadores citados"), habla de la reivindicación de Burckhardt por Cassirer, el cual replantea el problema sobre bases más complejas:

La novedad renacentista, en cuanto a la debatida cuestión de la conciencia de la individualidad, se manifiesta no tanto en el contenido mismo de la revelación autobiográfica como en su significación "funcional". Así, para refutar lo mantenido por Huizinga respecto a la antigüedad del sentimiento personalista del hombre

7 Obsérvese también la importancia que da Santillana a la música, como complemento de la poesía, y comparándola con el renacer de la naturaleza en la primavera: "Ponen sones asymismo a las sus obras e cántanlas por dulces e diuersas maneras, e tanto han familiar, acepta e por manos la música, que paresce que entr'ellos ayan nascido aquellos grandes philósofos, Orfeo, Pitágoras e Enpédocles, los quales, asý como algunos descriuen, non solamente las yras de los onbres, mas aun las furias infernales con las sonoras melodías e dulces modulaciones de los sus cantos aplacauan. E quién dubda que así como las verdes fojas en el tienpo de la primavera guarnescen e acompañan los desnudos árboles, las dulces bozes e fermosos sones no apuesten e acompañen todo rimo, todo metro, todo verso, sea de qualquier arte, peso e medida?" 
del Renacimiento, semejante para él al de Abelardo y Juan de Salisbury, Cassirer señalaba que el sentido de las formulaciones de Burckhardt podía resumirse en los siguientes términos: la presentación, biográfica o autobiográfica, de una figura individual, como tal figura individual, no había adquirido hasta la época renacentista un valor teórico universal ${ }^{8}$.

Esta reinterpretación obliga, en cierta medida, a dar al individualismo renacentista una dimensión nueva y a encuadrarlo quizá en una teoría mucho más complicada que la que a primera vista resalta en Burckhardt. La cuestión tiene interés especial en el caso del Marqués de Santillana. Pero si nos formulamos la pregunta: chasta qué punto se sentía Santillana un individuo, único e insustituible como tal?, veremos que, incluso en el caso de afirmar tal individualismo, ello no convertiría ipso facto a Santillana en un hombre del Renacimiento ${ }^{9}$.

Es muy posible que los ataques a Burckhardt se basen en un malentendido, y que su idea del individuo no sea precisamente lo que parece ser. En todo caso era quizá indispensable llamar la atención sobre el individualismo que surge antes del siglo Xvı, o incluso antes del xv, en los países situados en la periferia de Italia (tomando la palabra "individualismo" en su acepción ordinaria y corriente, y dando por supuesto, desde luego, que se puede tener consciencia de ser un individuo sin declararse por ello anarquista o solipsista). Tal fenómeno ha sido señalado y comentado ampliamente. Acerca de un poeta muy anterior a Santillana observa Hatzfeld:

Dos elementos nuevos penetran entonces (con los estilos góticos) en el arte medieval: el gesto individual y los primeros timidos signos de observación de la naturaleza. Y también caracterizan estos mismos elementos - psicología, naturaleza- las novelas rimadas de Chrétien, en contraste con las chansons de geste. iQué admirable detalle psicológico el hecho de que Enide, debido a su amor protector, descubra siempre antes que su marido a los enemigos que se acercan! En cierta ocasión, consciente de un peligro inminente, lo despierta incluso al dejar caer sobre su rostro una lágrima. Y si en Chrétien no hallamos ya prototipos de héroes sino personalidades distintas - Yvain, Gavain, Parsifal, Lanzarote-, tam-

8 J. Marichal, "Sobre la originalidad renacentista en el estilo de Guevara", NRFH, 9 (1955), p. 113.

9 Lo mismo ocurriría con la idea de la fama: María Rosa Luda de Malkiel ha señalado su existencia e importancia en la época medieval ( $L a$ idea de la fama en la Edad Media castellana, México, 1952; sobre Santillana, pp. 276-278). Examinados uno a uno, los criterios tradicionales para establecer si una obra es o no renacentista resultan hoy de imposible manejo, pues nos damos cuenta con mayor detalle de que existian ya mucho antes del siglo xv. El Renacimiento resultaría, pues, una ilusión. No hay tal: lo que es preciso ver es que la actitud renacentista fue resultado de una reagrupación de elementos tradicionales, una reagrupación que les dio nuevo sentido. 
bién en el tímpano de Notre Dame de París (fachada oeste, primera mitad del siglo $\mathrm{xm}$ ) cada profeta ostenta una barba diferente y distintos pliegues en sus ropas; cada rey sostiene su cetro en forma distinta. Cada personaje exige un tratamiento individual ${ }^{10}$.

El detallismo individualista resulta ser, pues, rasgo insuficiente en sí para determinar la proximidad o el alejamiento de un escritor o de un artista con respecto al clima espiritual del Renacimiento. Muchos pintores primitivos flamencos extreman los detalles individualizadores sin ser por ello plenamente renacentistas. Para ciertos hombres del siglo $\mathrm{xv}$-e incluso de siglos anteriores- fue posible, sin duda, sentirse a sí mismos como individuos sin saber a ciencia cierta en qué forma insertar su individualismo en el esquema del mundo circundante, que no parecía conceder al individuo un lugar adecuado o posibilidades de reorganizar los elementos que le estorbaban en cuanto individuo. $\mathrm{O}$ sea que el individualismo era, hacia esta época, una condición necesaria pero no suficiente para que un hombre pudiera llegar a esa plenitud y esa novedad en cuanto a puntos de vista, relaciones, valores, que llamamos Renacimiento. Hay huellas evidentes de autobiografismo y de consciencia del yo en los escritos de Santillana (el Prohemio, la Questión a don Alonso de Cartagena, ciertos poemas). El Marqués no se veía a sí mismo simplemente como un modelo, como prototipo del caballero castellano, sino como una modalidad bien individuada de cierto grupo social. Para saber qué hacer con su individualismo, Santillana -y es éste también el caso de muchos otros escritores de su tiempo, en particular de Mena- había de resolver previamente un problema de perspectiva mental y afectiva. Tal cosa no ocurre sino parcialmente, y sólo en dos de sus poemas, que más adelante analizaremos.

Señalemos otro fenómeno concomitante y paralelo: a la mayor parte de los artistas del siglo xv les es imposible resolver los problemas de la perspectiva ${ }^{11}$. Acumulan detalles concretos, pero esta acumulación hace aún más patente la falta de profundidad, de ordenación, de síntesis en numerosas obras de arte y literatura. Decorativismo, acumulación de detalles, aceptación no reelaborada de formas tradicionales: tales son los defectos más evidentes de la literatura y

10 Helmut HatzFeld, Literature through art: $A$ new approach to French literature, New York, 1952, p. 18.

11 "La solución de la perspectiva presentaba dificultades tanto para la literatura como para el arte. Un pintor como Henri Bellechose utiliza en el siglo xv prácticamente la misma técnica que un prosista como Joinville a principios del xIv. En ambos casos hay una presentación simultánea, ilógica, de acontecimien. tos que tienen lugar en momentos distintos. Es ésta una «falsa perspectiva en la medida en que se trata de una presentación superficial, sin ninguna profundidad de espacio ni de tiempo. Esta perspectiva errónea va acompañada de formas caprichosas y de una agrupación de las figuras según principios psicológicos más que lógicos" (H. Hatzfeld, op. cit., p. 55). 
las artes de la época, incluso en los más altos ejemplos. Por una parte, el detalle concreto; por otra, la alegoría o la queja derivada de los trovadores. Los fragmentos más insulsos de los cancioneros españoles del siglo xv hallan su paralelo en los textos de los rhétoriqueurs franceses. Jan van Eyck pinta a un canónigo sin perdonarle ni una arruga, ni un cabello desordenado, ni una verruga. Idéntico amor al detalle en el famoso políptico portugués de Nuno Gonçalves.

La escisión entre enumeración detallada de la ropa y los objetos, las partes del cuerpo, el mobiliario, las armas, etc., y la estructura alegórica, moralizadora, didáctica o teológica, no era estrictamente una novedad en el siglo xv. La tensión entre lo abstracto y lo concreto había dado ya origen a la posición nominalista en la teología y la filosofía medievales, a partir de una época muy anterior. El arte gótico se había humanizado, aumentaba la sensibilidad ante la naturaleza; pero el poner en contacto al hombre concreto con el orden ideal del universo, expresión de la voluntad divina, exigía un esfuerzo que los sucesores de Dante no podían ya alcanzar. Frente a tal situación, los escritores y artistas se refugian con frecuencia en el decorativismo, tan evidente en el gótico florido e incluso en el plateresco, o bien en el intimismo y la descripción de interiores, menos frecuente en la literatura española que en otras literaturas de la época. Las ideas o las situaciones de mayor complicación, "al aire libre", se resuelven gracias a la alegoría, la falsa perspectiva, las alusiones a la Antigüedad con función decorativa, el modelo cortés y trovadoresco con prestigio histórico y tradicional que ahorra el esfuerzo de descubrir una técnica nueva, un punto de vista no incluido en la tradición. De ahí el carácter decorativo de las alusiones clásicas, estetizantes, en buena parte de la obra de Santillana. De ahí el uso tan abundante de la alegoría, ambiguo punto de intersección entre lo concreto y visible y lo abstracto e ideal, que lleva con frecuencia a la posición didáctica y moralizadora, frecuente también en Santillana ( $y$ en Mena).

A Santillana y a Mena les falta ante todo la posibilidad de relacionar coherentemente y creadoramente el yo, la belleza femenina, la naturaleza, el mundo antiguo, el cosmos, la divinidad. El artista del Renacimiento hallará medios de relacionar estos elementos, de pasar sin tropiezo, con un mínimo de etapas intermedias, del uno al otro. La melancolía de Santillana, por ejemplo, es a menudo la tradicional melancolía derivada de la actitud trovadoresca en que se declara la ruptura de una relación o la imposibilidad de entablar contacto:

Crueldat e trocamento con tristeza me conquiso; pues me lexa quien me priso, ya non sey amparamiento. 
La cita es de Villasandino; Santillana la incorpora a su Querella de Amor. La dama lejana es vista en forma abstracta, como fuente de crueldad y dolor. La conclusión es en este caso moralizadora, y arraiga firmemente al poema en la tradición medieval:

Por ende, quien me creyere

castigue en cabeça agena;

e non entre en tal cadena

do non salga, si quisiere.

Garcilaso, en cambio, convertirá su dolor en parte integrante e inconmovible del mundo que lo rodea: "no me podrán quitar / el dolorido sentir..." Y para Calixto resultará fácil pasar de las ideas abstractas a la presencia concreta de Melibea, de esta presencia a su propio yo, del yo a la naturaleza, etc. Calixto es ya un hombre del Renacimiento.

Otra característica no renacentista de Santillana es su modo de ver la naturaleza. No le falta sensibilidad ni interés por ella, pero no consigue ver su belleza en forma independiente y autónoma: ha de asociarla a un marco social y cultural. Otro tanto ocurre con los poetas franceses anteriores al Renacimiento:

La naturaleza, que en su inmediatez primigenia resultaba atractiva para el pantésmo germánico y anglosajón, es aceptable para la sensibilidad latina de los franceses tan sólo en una forma refinada por el arte y cultivada por el hombre... Cuando Charles d'Orléans canta la llegada de la primavera, no halla modo de acercarse directamente a la naturaleza; ha de servirse de metáforas de la corte y la vida militar: la naturaleza ha abandonado su capa de invierno, de hielo, y su librea es ahora un vestido nuevo, bordado con sol; han llegado los furrieles del verano para decorar su alojamiento futuro con alfombras y tapices de flores ${ }^{12}$.

He aquí el conocido texto de Charles d'Orléans:

\section{Rondeau I}

Les temps a laissé son manteau de vent, de froidure et de pluye et s'est vestu de broderie de soleil luyant, cler et beau. Riviere, fontaine et ruisseau portent, en livrée jolie, gouttes d'argent d'orfaverie.

Chascun s'abille de nouveau.

12 Hatzfeld, op. cit., p. 48. 


\section{Rondeau II}

Les fourriers d'Esté sont venus

pour appareiller son logis, et ont fait tendre ses tapis de fleurs et verdure tissus.

En forma semejante Santillana describe, en una de sus más bellas serranillas, un acto amoroso dentro del marco de la naturaleza, sirviéndose de términos curialescos:
Asý concluymos
el nuestro processo
sin fazer excesso,
e nos avenimos.
E fueron las flores
de cabe Espinama
los encubridores.

Tras la delicadeza y la innegable belleza estilizada de las serranillas se descubre la imposibilidad de enfrentarse directamente con la belleza femenina y el amor sexual; el poeta necesita subrayar los elementos sociales (diferencia de clases, conflicto de valores entre la serrana y el caballero) y culturales (imágenes jurídicas en el ejemplo citado). Gil Vicente, en cambio, ya dentro de la corriente renacentista, podrá integrar la belleza de una doncella dentro de ciertos esquemas sociales y al mismo tiempo trascenderlos: en el conocido poemita del Auto da sibila Cassandra, las preguntas al marinero, al caballero, al pastor, tienden a situar la belleza femenina en distintas constelaciones de valores, con el resultado final de establecer una supremacía por doquier y de relacionar entre sí las distintas actividades y los distintos puntos de vista, reducibles uno a otro gracias al común denominador de la belleza femenina, valor aceptado por todos. $\mathrm{Y}$ es que la actitud renacentista consiste precisamente en haber resuelto un problema de comunicación, de perspectiva; en haber descubierto en los elementos del yo y del mundo circundante una "porosidad", un modo de relacionarse entre sí, que es precisamente lo que no consigue llevar a cabo Santillana ${ }^{13}$. Platonismo, redescu-

13 También para STEPHen Gilman es el Renacimiento, ante todo, una cuestión de perspectiva, de integración del hombre, como microcosmos, en la totalidad del paisaje: "The use of perception as a guide to reality [was] essential to the Renaissance... Garcilaso was among the first to feel the new importance of seeing and hearing the gentleness of a flowing brook. That his was a poetic rather than an actual gaze is not a valid objection; the new value created by the act of looking is the important innovation...; the new immanence, the new centering of man within perspective, which the pastorals represent, was the distinguishing feature of the Renaissance" ("An introduction to the ideology of Baroque in Spain", $S$, 1946, núm. I, pp. 88-89). 
brimiento de la Antigüedad, relaciones matemáticas, son algunos de los métodos que los hombres renacentistas emplearán: todo ello contribuye, en gran parte, a las nuevas teorías estéticas que permiten aplicar esos principios a las artes. Otros caminos eran, quizá, posibles: la reinterpretación de los trovadores ${ }^{14}$, o la actitud mágica, evidente en un renacentista como Paracelso ${ }^{15}$. Esencialmente, en breve esquema, el problema consistía en pasar de la experiencia concreta a la belleza ideal.

$\mathrm{Y}$ no es ciertamente la experiencia concreta lo que falta en Santillana. Muy concretas son, en sus serranillas, las anotaciones de lugar y de tiempo:

$$
\begin{aligned}
& \text { Madrugando en Robledillo } \\
& \text { por yr buscar un venado... } \\
& \text { Entre Gaona e Salvatierra, } \\
& \text { en esse valle arbolado } \\
& \text { donde s'aparta la sierra, } \\
& \text { la vi guardando ganado, } \\
& \text { tal como el alvor del día, } \\
& \text { en un hargante de grana... }
\end{aligned}
$$

Suelen partir estas composiciones de una experiencia concreta -o descrita como tal-, y terminar también con una afirmación concreta, limitada a la experiencia personal del poeta:

14 "En moldes petrarquistas entra toda la materia del amor cortés, de la que el Canzoniere había sido cima y transformación" (LAPEsA, op. cit., p. 187). Petrarca parte de un "amour lointain", como los trovadores; la transformación consiste en convertir sistemáticamente a la naturaleza en eco y amplificador de sus sentimientos de soledad y desamparo: "Si ch'io mi credo omai, che monti, e piagge, / e fiumi, e selve sappian di che tempre / sia la mia vita, ch'è celata altrui. // Ma pur sì aspre vie, ne sì selvaggie / cercar non so, ch'Amor non venga sempre / ragionando con meco, ed io con lui" (Soneto XXII). Cuando Santillana toma por confidentes a las "doradas ondas del famoso río" que baña la ciudad donde se encuentra su amada (Soneto $X X$ ), o cuando escribe: "Nin son bastantes a satisfazer / la sed ardiente de mi grand deseo / Tajo al presente, nin me socorrer // la enferma Guadiana, nin lo creo: / solo Guadalquivir tiene poder / de me guarir, e solo aquél deseo" (Soneto XIX), se halla plenamente dentro de esta línea que es, en realidad, renacentista. Del amor cortés perdura, en cambio, el sentimiento melancólico de la pérdida; la ausencia, que impide llegar al entusiasmo y a la alegría que a menudo hemos asociado con el Renacimiento. Pero, claro está, tal observación se aplicaría también a buena parte de la obra de Garcilaso, de la cual no duda nadie que sea plenamente renacentista.

15 Paracelso combatió el formalismo aristotélico acudiendo al "libro de la naturaleza" y a la observación directa de los detalles y las variaciones locales; pero cuando trató de hallar una base teórica para sus investigaciones, no tuvo más remedio que recurrir (a través del neoplatonismo, en parte, y de la cábala) a la vieja idea mágica de que a cada parte del microcosmos humano corresponde una parte del macrocosmos de la naturaleza. Esta idea, latente durante la Edad Media, se desarrolla con particular vigor durante el Renacimiento. 
Si voluntat no m'engaña, no vi otra más graciosa.

La verdat, que tan loçana, aprés la señora mía, non vi doña nin serrana.

Díxele: "De tal ensayo, serrana, soy plazentero".

$\mathrm{Y}$ entre dos experiencias concretas se desarrolla el poema, que suele ser una descripción del aspecto físico concreto de la serrana, seguida del diálogo entre ésta y el caballero.

En la obra de Santillana figura también, claro está, lo abstracto y alegórico:

¿Dó es la fee? ¿Dó es la caridad?

¿Dó la esperanza? ca por cierto ausentes son de las tus regiones e partidas.

¿Dó es la justicia? Templança, egualdad, prudencia e fortaleça, ¿son presentes?

(Soneto XVIII)

Amor cruel e bryoso, mal aya la tu alteza, pues no fazes igualeza, seyendo tan poderoso.

(Querella de Amor)

Lo que no hallamos en él, lo que sólo será posible más tarde, es el paso rápido de lo concreto a lo abstracto, el " $\mathrm{Oh}$ dulces prendas por mi mal halladas...!" Hacia mediados del siglo xir había escrito ya Roger Bacon acerca del problema de lo concreto y lo abstracto: ". . la experiencia es doble: una parte procede de los sentidos exteriores..., pero esta experiencia no le basta al hombre..., no afecta para nada a las cosas del espíritu. Por lo tanto, es necesario que la comprensión del hombre reciba otra ayuda, y así los santos patriarcas y profetas, que fueron los primeros en dar las ciencias al mundo, recibieron iluminaciones interiores y no dependieron únicamente de los sentidos" ${ }^{16}$. Bacon era nominalista. Santillana es también nominalista cuando, después de describir a una serrana (Serranilla $V$ ):

Pellote negro vestía

e lienzos blancos tocava,

a fuer del'Andaluzía,

e de alcorques se calçava...,

${ }_{16}$ Cit. por A. C. CRombie, Robert Grosseteste and the origins of experimental science, 1953, cap. 2. 
adopta a continuación el punto de vista abstracto, impersonal, alegórico, sin que el lector moderno pueda comprender el porqué de la nueva postura:

$$
\begin{aligned}
& \text { Si mi voluntad agena } \\
& \text { no fuera, en mejor logar, } \\
& \text { non me pudiera excusar } \\
& \text { de ser preso en su cadena. }
\end{aligned}
$$

No hay en la descripción anterior, de la ropa y el tocado de la serrana, nada que justifique ipso facto la transición hacia la "cadena" de Amor. No hay, en realidad, transición, sino yuxtaposición de dos posturas antitéticas. La "cárcel de Amor" es una abstracción; el llegar a ella partiendo del pellote y los alcorques, un ejercicio literario $^{17}$

Santillana, que se ve a sí mismo como individuo, como "caso especial" dentro del molde caballeresco ("la sciencia non enbota el fierro de la lança, ni faze floxa la espada en la mano del cauallero"), que ve en la poesía "un zelo celeste, una affección divina, un insaciable cibo del ánimo", que cree que el hombre es educable, que da gran importancia al estudio de idiomas antiguos y modernos y a las traducciones, que conoce y cita a muchos autores clásicos y está al corriente de buena parte de la cultura de su época, que afirma, finalmente, que "lo inperfecto [busca] la perfección" (Prohemio), parece reunir objetivamente las condiciones necesarias para alcanzar la sensibilidad renacentista. Le falta, sin embargo, el catalizador de una posición estética nueva; hay demasiado didactismo en su actitud de artista ("toda arte, doctrina e deliberación es a fin de alguna cosa", cita, significativamente, en la introducción a los Proverbios, subrayando así la interpretación didáctica de Aristóteles en la época medieval). La pura contemplación estética, sin finalidad ulterior aparente, quizá le hubiera permitido conseguir el acceso a la postura plenamente renacentista, al borde de la cual se hallaba. Pero tal contemplación le resultaba sobremanera difícil; a ella se oponía, por una parte, el moralismo medieval ("yerran aquellos que pensar quieren o dezir que solamente las tales cosas [la poesía] consistan e tiendan a cosas vanas e lasciuas", como dice en actitud defensiva en el Prohemio), y por otra la identificación con la tradición trovadoresca.

$17 \mathrm{Y}$ además, un ejercicio peligroso. Todo lo que sea pasar de los accidentes a la sustancia, del estar al ser, acerca al poeta al terreno de la teología. En realidad, el único que puede saltar tan altas barreras es Dios: "Bien sabes, dolorida España, que el tu sí era si, e el tu no era no; por consiguiente la fee, la verdad e fortaleça del mundo era constreñida en ti sola, e el tu Dios honrado e adorado, de lo qual el día de ayer es despojado e convertido en otra desordenada substancia. E non sabes que la innumerable e inmensa Substancia jamás non perdona a los baxos nin altos, nin cessarán jamás los tus maravillosos accidentes" (Lamentación fecha por el Marqués en prophecia de la segunda destruyción de España). 
Santillana es sensible a la cadena de la tradición: "Pero éstos que he dicho, lo que ordenaron e fizieron, de otros lo tomaron, e los otros de otros, e los otros de aquellos que por luenga vida e sotil inquisición alcançaron las experiencias e causas de las cosas", afirma a propósito de sus Proverbios ${ }^{18}$.

En el Cantar que fizo. . . a sus fijas loando la su fermosura, llega Santillana a una actitud ante la belleza femenina mucho más deliberada y consciente que en sus otros poemas. En la Comedieta de Ponza había descrito ya una belleza ideal, supraterrena, con "deslumbradora ostentación de vestiduras y piedras preciosas, escudos y banderas...: "quasi deesas» parecen las cuatro señoras" (LAPEsA, op. cit., p. 141). En las serranillas, la belleza de las muchachas se describe, en general, con relativa brevedad, y se enmarca siempre en la naturaleza, sentida en su varia y sabrosa realidad geográfica. Pero en el Cantar, la naturaleza aparece como simple telón de fondo, reducido a un mínimo, y en borrosa función de contraste frente a la belleza lujosa de las doncellas:
Dos serranas he trovado a pie de áspera montaña, segund es su gesto y maña, non vezadas de ganado.

En las serranillas, la belleza femenina es parte de un todo; aquí la descripción está exenta de precisiones geográficas, de acción, de diálogo. Las reticencias anteriores frente a la descripción detallada de la belleza femenina desaparecen aquí, en este "retrato de familia" en que, al fin y al cabo, el Marqués está describiendo a sus hijas:
Carnoso, blanco e liso
cada qual en los sus pechos,
porque Dios todos sus fechos
dexó quando fer las quiso:
dos pumas de paraýso
las sus tetas ygualadas,
en la su cinta delgadas
con aseo adonado.

18 Las dificultades de Santillana distan mucho de ser únicas. Acerca de la literatura francesa, y refiriéndose a época posterior, dice HATzFELD, op. cit., p. 55: "El enfoque plenamente pagano en cuanto a la belleza femenina no resulta visible en la primera mitad del siglo xvi. Sigue prevaleciendo el sentimiento de que la belleza debe quedar contrapesada por la fealdad, la juventud por la vejez, la vida por la muerte. Así como Villon pintó en el siglo xv un doble retrato de la joven y la vieja belle heaulmière, con un detalle anatómico, una melancolía y un sarcasmo admirables, así también Clément Marot, en el xvi, se atreverá a escribir su blason du beau tétin gracias a que lo contrasta con el blason du laid tétin". 
Es verdad que en la tradición literaria del retrato femenino es posible hallar rasgos semejantes ${ }^{19}$. Pero aquí hay algo distinto: en primer lugar, se trata de una novedad dentro de la obra de Santillana; y en segundo lugar, el pudor del Marqués desaparece, debido, en parte, al carácter no erótico de la relación familiar, y en parte también a que el poema transforma la presencia femenina en algo irreal, en un cuadro, en una miniatura:

$$
\begin{aligned}
& \text { Yo las vi, sí Dios me vala, } \\
& \text { posadas en sus tapetes, } \\
& \text { en sus faldas los blanchetes } \\
& \text { que demuestran mayor gala. }
\end{aligned}
$$

Las "serranas" son, pues, damas nobles; están sentadas sobre alfombras; sus dedos, con "uñas de argent guarnidas", acarician unos perrillos blanchetes. Las nobles doncellas están posando para su padre. La ausencia de comitiva o cortejo subraya aún más el carácter irreal de la escena: es un "interior" palaciego transportado de pronto al pie de un áspero monte. Y la visión estática - no hay un solo verbo de movimiento antes del final- acentúa el carácter de "obra de arte" a través del cual Santillana se acerca aquí a la belleza femenina. Al final, el Marqués se incorpora, a su vez, al cuadro:

$$
\begin{aligned}
& \text { Los finojos he fincado, } \\
& \text { segund es acostumbrado } \\
& \text { a dueñas de gran altura; } \\
& \text { ellas, por la su mesura, } \\
& \text { en los pies m'an levantado. }
\end{aligned}
$$

Este final silencioso contribuye también al efecto desrealizador. El diálogo habría roto el encanto; un homenaje silencioso, de cortesía hasta cierto punto absurda, realza el carácter especial de la contemplación del poeta. Privado de sus reminiscencias trovadorescas, en la imposibilidad de transformar a sus hijas en alegorías, Santillana nos ofrece un momento de contemplación estética en que se funden arte e intimidad, en que una belleza femenina estática se convierte en visión plástica, doblemente inocente por tratarse de las hijas del poeta y porque las doncellas tienen los gestos inmóviles de las figuras de un cuadro. La descripción queda enmarcada por dos momentos que se separan del cuerpo del poema: la declaración irónica inicial de que se trata de dos "serranas", y el gesto de homenaje final con que el poeta se incorpora a la obra de arte que acaba de crear ${ }^{20}$.

19 Cf. María Rosa Lida, "Notas para la interpretación, influencia, fuentes y textos del Libro de buen amor", RFH, 2 (1940), pp. 122 ss.

20 El que el poeta aparezca como parte del cuadro que describe nos pone, quizá, en presencia de lo que Américo Castro llama la "actitud centáurica", esa tendencia de escritores y artistas de épocas bien diversas a incorporarse a 
$\mathrm{Y}$ todo ello en forma, tal vez, algo descuidada; más que de un cuadro pacientemente elaborado, se trata de un esbozo, al que quizá no concedía gran importancia el poeta ${ }^{21}$.

El poema es quizá de 1444 ó $\mathbf{1 4 4 5}$. En las serranillas, escritas anteriormente, en la plena madurez poética de Santillana, se trazaba una "geografía poética de Castilla" ${ }^{22}$; los rasgos procedentes de la tradición cortés se combinaban en ellas con detalles directamente observados, y su gracia refinada llegaba a una cumbre difícil de superar. Lo que intenta el Cantar a sus hijas es otra cosa: las doncellas quedan elevadas estéticamente a una condición menos real y humana, tal vez, que alguna de las serranas, pero más auténtica y vital que las alegorías; son quienes son, sin dejar de ser al mismo tiempo obras de arte, figuras de tapicería evocadas ante un fondo de montañas. Nos hallamos ante un paisaje con figuras; el fondo, sombrío, hace resaltar el brillo de las joyas y las ricas ropas, la suave blancura de las carnes. Las figuras, es cierto, dominan el paisaje; triunfa el lujo suntuario sobre la "áspera montaña", y el suelo desnudo se cubre de alfombras. El contraste contribuye así a enmarcar a las damas, a concentrar sobre ellas la mirada del poeta y de sus lectores. La naturaleza estaba presente, en mayor o menor grado, en todas las otras serranillas. En el Cantar está más bien latente. Por una parte, las palabras serranas, áspera montaña, ganado, obligan al lector que conoce las otras serranillas a evocar, tal vez inconscientemente, los rasgos descriptivos y campestres de esos poemas; por otra, la continuación del Cantar deja en la sombra este conato descriptivo y lo convierte en constraste irónico.

El poema no es, pues, plenamente renacentista, si por actitud renacentista entendemos una contemplación en que la figura humana, la naturaleza circundante y el cosmos todo se hallan unidos por una serie de relaciones armónicas que el hombre, dotado de dignidad especial, y consciente de la tradición clásica, puede comprender y reproducir. Hay en el Cantar contemplación estética, goce en la "belleza por la belleza", transformación de esta belleza en obra de arte. Hay incluso, quizá inconscientemente, una forma nueva de manejar la perspectiva: la visión algo plana de la descripción central se ensan-

sus obras. El autobiografismo de Berceo o del Arcipreste de Hita son, sin duda, ejemplos medievales de esta postura integradora. Pero ambos incluyen su personalidad en un conjunto que dista mucho de ser una estática descripción plástica; la incorporación es, en ambos casos, más dramática que estética.

21 "Poema quintaesenciado y artificial, no muestra, sin embargo, elaboración primorosa... Hay algún descuido en las rimas y alguna estrofa con más versos que las demás. Todo parece denunciar que el Marqués dio poca importancia a este poema circunstancial, destinado a la intimidad familiar: lo dejó sin retocar en su redacción primera; y no lo recogieron después los principales manuscritos que coleccionaron sus obras" (LApEsa, op. cit., p. 65).

22 Cf. G. Cirot, "La topographie amoureuse du Marquis de Santillane", BHi, 37 (1935), p. 392 . 
cha al final para dar paso a la figura del poeta, y parece cobrar con ello mayor profundidad. El poeta se acerca a la belleza utilizando procedimientos pictóricos que la transforman en obra de arte y despojándola, además, de toda posibilidad de engendrar sentimientos demasiado poderosos y turbadores, que habrían evocado posturas tradicionales moralizadoras o trovadorescas, y se queda en actitud de observador tierno y orgulloso de la belleza de sus hijas. Todo ello le permite una serena contemplación, desprovista de problemas, en que se concentra un goce puro, sensual y estético. Los procedimientos de la pintura le han facilitado sobremanera esta contemplación: el silencio y la falta de movimiento hacen posible prolongar la morosa y descriptiva actitud del Marqués. Pero para llegar a una actitud plenamente renacentista habría que añadir a la contemplación de la belleza un rasgo que aquí todavía falta: el sentimiento de que de la belleza descrita nace una armonía. Y este sentimiento sí se halla en otro poema de Santillana, el famoso Villancico fecho... a unas tres fijas suyas.

Entre el Villancico y el Cantar hay varias semejanzas. La relación fundamental es la misma: un observador, unas damas, un malentendido inicial que la marcha del poema se encarga de disipar. Otro rasgo común es la ironía: también en el Villancico se equivoca el poeta, aunque la equivocación es ahora más grave. Sabe que se halla frente a "tres damas fermosas", pero no cae en la cuenta de que son sus hijas. A esta ambigüedad inicial, que le permite -al principio por lo menos- contemplar a sus hijas como mujeres hermosas y apetecibles, se añade el desengaño final, resuelto y sublimado gracias a la armonía de la música. Hay movimiento, contacto humano, diálogo, a diferencia del Cantar. El marco del Villancico es la "gentil floresta" estilizada de la tradición:

\section{Por una gentil floresta de lindas flores e rosas, vide tres damas fermosas que de amores han reqüesta.}

El poeta introduce rápidamente su propia presencia de observador interesado y el tema musical de la dama que revela su posición ante el amor mediante un cantarcillo popular:

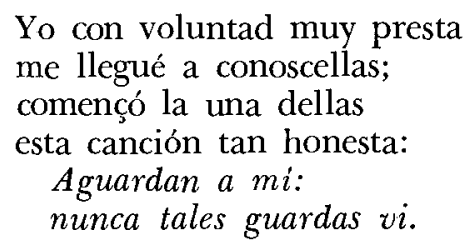

El observador queda puesto entre paréntesis, oculto a la vista de las 
damas, que no se han fijado en él todavía; escondido, examina mejor a las damas y escucha sus cantos:

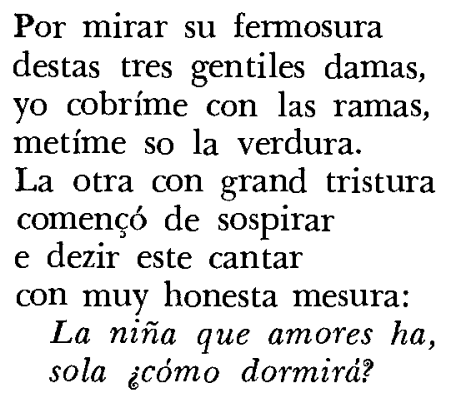

Se establece así un punto de vista especial y fijo, en que las damas quedan como enmarcadas por las verdes ramas tras las cuales las observa el poeta; a la primera melodía se añade una segunda. El poeta sigue escondido:

$$
\begin{aligned}
& \text { Por no les fazer turbança } \\
& \text { non quise ir más adelante } \\
& \text { a las que con ordenança } \\
& \text { cantavan tan consonante. } \\
& \text { La otra con buen semblante } \\
& \text { dixo: "Señoras de estado, } \\
& \text { pues las dos avéys cantado, } \\
& \text { a mí conviene que cante": } \\
& \text { Dexaldo al villano pene: } \\
& \text { véngueme Dios déle. }
\end{aligned}
$$

El poeta, entristecido al comprender que las damas han hecho ya entrega de su amor, abandona su escondite (su "punto de vista a cierta distancia del cuadro") y se presenta ante ellas:

$$
\begin{aligned}
& \text { Desque ya ovieron cantado } \\
& \text { estas señoras que digo, } \\
& \text { yo salí desconsolado, } \\
& \text { como hombre sin abrigo. }
\end{aligned}
$$

Las damas han expresado sus quejas por la vigilancia que entorpece la relación entre amada y amado ("Aguardan a mí..."), el insomnio producido por la pasión amorosa ("La niña que amores ha...") y la represalia contra el enamorado infiel ("Dexaldo al villano pene..."). El poeta, al presentarse con su tristeza frente a las damas, parece introducir una nota discordante, bien pronto resuelta en armonía al ser, a su vez, invitado a cantar: 
Ellas dixeron: "Amigo, non soys vos el que buscamos;

mas cantad, pues que cantamos".

Dixe este cantar antigo:

Sospirando yva la niña,

$e$ non por $m i$,

que yo bien se lo entendi.

Lo curioso es que el efecto de suave melancolía renacentista que esta obra produce esté conseguido mediante una mezcla de elementos tradicionales ${ }^{23}$. Pero ¿acaso la actitud renacentista es una creación ex nihilo? ¿No es acaso una disposición y organización nueva de elementos que se pueden hallar ya en diversos autores medievales? ¿Y no es la conexión y el sentido que el autor renacentista les da lo que produce la sensación de novedad y de descubrimiento? En el $\mathbf{V i}$ llancico hallamos, sobre todo, que los procedimientos estetizantes del Cantar se intensifican y adquieren una dimensión nueva. La emoción del poeta se integra a un conjunto estético, y el yo individual queda superado mediante la armonía de las voces y la invitación, aceptada por el poeta, a cantar y disipar así su melancolía. El Villancico, dice Lapesa (op. cit., p. 73), "no es una sucesión de monodías antitéticas: cada una de las damas inicia un tema («començó la una dellas»; "començó de sospirar / e dezir este cantar»); pero las demás la acompañan entrando en los momentos debidos ("con ordenança / cantavan tan consonante»)". O, como observa Leo Spitzer, "lo peculiar del poema de Santillana está en el arte con que logra ensamblar cuatro estribillos populares distintos que ha coleccionado y que ha tratado como otras tantas piedras preciosas antiguas que necesitan un nuevo engaste de acuerdo con la moda del día... Las diversas emociones se funden, templan y subliman por medio de canciones polifónicas. . . El efecto final de «concierto a cuatro voces» es el del amor templado por la melancolía... Así, los estribillos populares, creados para expresar sentimientos espontáneos y sencillos, son elevados por Santillana al plano de un arte ingenioso y reflexivo" 24 .

Llegamos a una suave melancolía petrarquesca gracias a la armonía musical, en que la cultura -cultura musical- permite establecer un nexo entre el yo dolorido del poeta y el resto del universo. En Petrarca, el dolor es suavizado al hallar un eco en la naturaleza; aquí, al expresarse mediante "mesura", música y armonía. La emoción no queda reducida a lo concreto inexpresable ni a lo abstracto y gene-

23 "Lugar común. . era el encuentro del poeta con gentiles personajes femeninos en un vergel convencional; frecuente era también que el narrador, para ver o escuchar, se escondiera entre el boscaje. Unidos o no, los dos rasgos aparecen repetidamente a ambos lados del Pirineo" (LAPEsA, op. cit., p. 69).

$2 \pm$ L. SpITzer, "The Mozarabic lyric...", art. cit., p. 14, nota. 
ral; el poeta ha hallado un puente entre el yo dolorido y la armonía del mundo que lo rodea. Se borra así toda sombra de didactismo. Nos quedamos con un vaivén entre la contemplación estética inicial, el interés amoroso defraudado -emoción frustrada- y la liberación final de la emoción en un conjunto más vasto y armónico, en que el individuo se incorpora a su ambiente tras haberse sentido plenamente individuado y "aparte". La visión estética y la armonía musical, al expresar el punto de vista del poeta, consiguen fundir los contrastes y restablecer el equilibrio.

Hemos apuntado anteriormente en qué forma los problemas del arte gótico giraban alrededor del desequilibrio entre lo abstracto y lo concreto, y la imposibilidad de hallar un puente entre los dos, especialmente grave en el arte profano. (La Virgen dorada de Amiens no parece tener dificultad en ser a la vez divina y muy humana). La gran excepción, naturalmente, es la Divina Commedia, que consigue establecer el contacto mediante un sistema muy elaborado de símbolos y alegorías. Pero en la literatura del siglo xv ya no es posible reproducir semejante esfuerzo. De ahí que todo, en el gótico florido, tienda a la estilización, al decorativismo, o a la alegoría. Para hallar salida a una actitud nueva era preciso acudir a un sistema - matemáticas, música, neoplatonismo- que organizara las relaciones armónicas entre la parte y el todo, entre el individuo y el cosmos. "La primera premisa del artista del Renacimiento es la santidad de la relación matemática, que se revela a la vez filosófica y científicamente en el neoplatonismo. La más famosa definición renacentista de la Belleza se halla en el tratado de Alberti De la arquitectura (1452): «Defino la Belleza como una armonía de todas las partes, sea cual fuere el asunto o lugar en que aparezca, ensambladas con tal proporción y conexión, que nada pueda añadirse, disminuirse ni alterarse»..."25 A diferencia de Mena, antipopular y decorativista en el empleo de las alusiones clásicas, el Marqués de Santillana llega en su Villancico, gracias a un conjunto de factores -intimismo liberador del sentimiento, delimitación esquemática y como de viñeta de un "poema de circunstancias", uso de la armonía musical y del tema popular de la serranilla que consigue la unión del poeta con las "circunstancias" del mundo que lo rodea-, a una "armonía de todas las partes" en que hallamos ya los primeros acentos, quizá todavía inconscientes, del Renacimiento español.

Manuel Durán

Yale University.

25 WYlie SYPher, Four stages. ., op. cit., p. 62. 